\title{
Prolactin Level and Breastmilk Production among Mothers of Low-Birth-Weight Infants Admitted to Level II Neonatal Intensive Care Unit
}

Jessica Anne A. Dumalag, MD, ${ }^{1}$ Maria Esterlita T. Villanueva-Uy, MD, MSPH ${ }^{1}$ and Peter Francis Raguindin, MD, MSc ${ }^{2}$

${ }^{1}$ Division of Newborn Medicine, Department of Pediatrics, Philippine General Hospital, University of the Philippines Manila

${ }^{2}$ Institute of Child Health and Human Development, National Institutes of Health, University of the Philippines Manila

\begin{abstract}
Background. Kangaroo mother care (KMC) has been proven by several studies to promote breastfeeding, but many of the studies focus on the success of exclusive breastfeeding, and less on its galactogenic effects.

Objective. We aim to determine the maternal serum prolactin levels and breastmilk volume of mothers who rendered $\mathrm{KMC}$ to their infants.

Materials and Methods. This is a randomized controlled, open-labeled, interventional study in the Neonatal Intensive Care Unit of a tertiary government hospital. Infants weighing < 2000 grams admitted in NICU Level II, together with medically stable mothers and no contraindication for breastfeeding were simultaneously enrolled. Primary outcome measures were maternal serum prolactin levels and expressed milk volume on day 3 and day 7 postpartum. Two-sample t-test was used to compare groups, and paired t-test to compare within groups. Tests were two-tailed, with a $\mathrm{p}$-value of $<0.05$ considered statistically significant.
\end{abstract}

Trial Registration. Australia-New Zealand Clinical Trial Registry ID ACTRN12614000218695

Results. Fifty mother-infant dyads were equally allocated into KMC and control groups $(p<0.001)$. There was significantly larger milk volume on the third day $(29.6 \pm 27.8 \mathrm{~mL}$ vs $16.3 \pm 26.1 \mathrm{~mL} ; \mathrm{p}<0.001)$ and seventh postpartum day $(72.4 \pm 62.3 \mathrm{~mL}$ vs $47.3 \pm 43.8 \mathrm{~mL} ; \mathrm{p}<0.000)$. There were increased serum prolactin levels compatible with post-partum state. The increase was more evident in the KMC $\left(5244 \pm 2702 \mathrm{mlU} / \mathrm{L}\right.$, on the $3^{\text {rd }}$ postpartum day versus $4969 \pm 2426 \mathrm{mlU} / \mathrm{L}$, on the $7^{\text {th }}$ postpartum day, $\left.p=0.996\right)$ compared to control group $(4129 \pm 2485 \mathrm{mlU} / \mathrm{L}$ on the $3^{\text {rd }}$ postpartum day versus $3705 \pm 2731 \mathrm{mIU} / \mathrm{L}$ on the $7^{\text {th }}$ postpartum day, $p=0.301$ ).

Conclusion. We noted a significantly larger milk volume in the KMC group. There was also a greater increase in the prolactin levels in the KMC group, but this did not reach statistical significance. Further studies should be done to determine mechanism of galactogenesis through KMC.

Key Words: Kangaroo mother care, galactagogue, prolactin

Paper presented in the Annual Meeting of the Academy of Breastfeeding Medicine on October 16-18, 2015, at California, USA.

Partial results of the study were presented at the $10^{\text {th }}$ International Kangaroo Mother Care Conference on November 17-19, 2014, at Kigali, Rwanda.

Corresponding author: Peter Francis Raguindin, MD, MSc Institute of Child Health and Human Development National Institutes of Health

University of the Philippines Manila

$112 \mathrm{G} / \mathrm{F}$ National Institutes of Health Bldg.,

623 Pedro Gil St., Ermita, Manila 1000, Philippines

Email: pnraguindin@up.edu.ph

\section{INTRODUCTION}

Kangaroo mother care (KMC) is a novel technique developed by Rey in 1978 for the care of low birth weight infants. ${ }^{1,2}$ It is conceptualized for use in neonatal intensive care units (NICU) with limited resources due to lack of incubators, increased nosocomial infection, high neonatal mortality, and increasing rates of infant abandonment. ${ }^{3}$ Its major components include early skin-to-skin contact, exclusive breastfeeding, and early discharge from the hospital. ${ }^{2-4}$ It has gained wide acceptance in several countries as a cost-effective way of decreasing mortality and 
morbidity of preterm infants. ${ }^{5}$ Several studies have been done with regards to the benefits of KMC. It has been studied for use in analgesia, ${ }^{6}$ thermoregulation, ${ }^{7}$ metabolism, ${ }^{8}$ growth, ${ }^{9}$ and infection-control ${ }^{2,10}$ among others. Conde-Agudelo did a meta-analysis in 2011 investigating the effects of KMC on the overall reduction of mortality and morbidity for low birth weight infants. ${ }^{10}$ Their review shows a reduction of infant morbidity without any adverse effects.

Early skin-to-skin contact, which is a major component of this $\mathrm{KMC}$, has a beneficial effect in increasing breast milk volume. ${ }^{11}$ One theory on its galactogenic effect is the relief of stress and anxiety that are both antagonistic to maternal lactation. ${ }^{12}$ It results in a more positive view of mothers on caring for their newborns. Another hypothesis is the increased sensitivity of mothers to their infant's hunger cues due to non-separation of the dyad. ${ }^{13}$ Mothers are more aware of their baby's needs and patterns of behavior; this leads to more frequent feeding, which subsequently leads to increased breastmilk production.

Human prolactin (PRL) is a $23 \mathrm{kDa}$ protein consisting of 199 amino acids that is secreted by the anterior pituitary gland. ${ }^{14}$ It has varied functions in the body, the most notable of which is its action on lactogenesis. Several trials have reported a direct relationship of serum prolactin levels with breast milk volume, ${ }^{15,16}$ and supplementation of pharmacologic preparations have been used in lactational disoders. ${ }^{17,18}$ Several factors were observed to stimulate prolactin secretion including skin-to-skin contact, emotional state of the mother, and infant's presence. ${ }^{19,20} \mathrm{KMC}$ involves several maneuvers that can collectively increase prolactin secretion. This study determined if $\mathrm{KMC}$ will result to increase in serum prolactin levels and increase in breastmilk production.

This study aims to determine if $\mathrm{KMC}$ will result in to increase in serum prolactin levels and increase in breast milk production. This may contribute to establishing a physiologic proof of the galactogenic effects of KMC.

\section{METHODOLOGY}

\section{Study Design}

We conducted this prospective, randomized, controlled, open-labeled, interventional study in the NICU Level II of the Philippine General Hospital. NICU Level II is a unit that takes care of infants who do not require oxygen support and are deemed to have a stable physiological and clinical profile by the neonatologist-on-duty. The usual indications for admission in this unit include, but are not limited to, prematurity, low birth weight, pathologic jaundice, neonatal sepsis, and other physiologically stable neonatal condition (e.g., congenital malformations and dysmorphisms).

\section{Enrollment criteria}

All infants born within the time period who satisfied the enrollment criteria were invited to join the study. Inclusion criteria were: (a) weight of $\leq 2000 \mathrm{~g}$, and (b) Apgar score $\geq$ 7 at 5 minutes of life. Exclusion criteria were: (a) Unstable infants namely extremely low birth weight (ELBWs), infants with chromosomal and life-threatening congenital anomalies, and infants with oxygen or cardiovascular support, (b) clinically unstable mothers who cannot render $\mathrm{KMC}$, (c) mothers who have contraindication for breastfeeding, and finally (d) mothers diagnosed with prolactinoma.

\section{Study procedures}

Enrolled mother-baby dyads were assigned an identification code to ensure anonymity and concealment of allocation to the outcome measurers. The sequence of allocation was generated using random numbers in a statistical program. All eligible dyads were randomly allocated using sequentially numbered opaque sealed envelopes, equally distributed between $\mathrm{KMC}$ and control groups (50:50 group allocation). After allocation into groups, a patient database sheet was completed by NICU personnel containing the baseline characteristics. All mothers underwent basic training of routine newborn care conducted by the pediatric nurses.

Mothers assigned in the KMC group underwent special training on the proper procedure for the intervention. The babies were placed on a prone position with the head tilted on the side facing the mother. A cloth was also placed to cover the mother's chest and the baby. Mothers rendered $\mathrm{KMC}$ by placing their infants on their chest for at least four hours daily for seven days. A study nurse monitored the vital signs of both the baby and the mother during the procedure. After the procedure, the baby was placed back in the bassinet and the mother was sent back to the general ward.

Infants of both groups received the standard care, which includes, feeding of expressed breast milk by cup, thermoregulation, and phototherapy as prescribed. Infant groups were monitored for heart rate, respiratory rate, and temperature. Any untoward events such as hypothermia, hypoglycemia, apnea, signs of sepsis, and feeding problems were noted, and the involved participants were immediately withdrawn from the study.

\section{Outcome measurement}

Serum prolactin level was determined on day 3 and day 7 after the delivery. $4 \mathrm{~mL}$ blood samples were taken from the mothers after 3 successive breast milk extraction for motherbaby dyad in KMC group. For the dyads in control group, blood samples were collected from the mother in the morning. Serum samples were sent to the Radioisotope Laboratory for prolactin assay (measured in $\mathrm{mIU} / \mathrm{L}$ ). Samples carried were labeled with study ID. Laboratory technicians who processed the samples were blinded to the treatment allocation.

All mothers underwent milk extraction using machine pump assisted by the lactation nurses. Breast milk collection was done three consecutive times every three hours each on day three and day seven after delivery. Lactation nurses, 
who were not involved in the study and were blinded as to the allocation, measured and recorded the volume of breast milk on a logbook. The best of the three values was used for analysis.

\section{Statistical Analysis}

A sample size of 25 participants for each arm was calculated to achieve a power of $80 \%$ and an alpha error of 0.05. Baseline characteristics for both arms were described using means (and standard deviation) for continuous variables and frequency (and percentage) for categorical variables. We used simple t-test and chi-square test for continuous and categorical data, respectively. For milk volume and prolactin outcomes, we performed Shapiro-wilk for test of normality. We log-transformed both outcomes before statistical testing. We used the two-sample t-test to compare outcomes of the two arms at baseline, and the paired t-test to compare outcomes across the period. Tests were performed two-tailed, with a p-value of $<0.05$ considered statistically significant. All analysis was performed using STATA 15.1 (Texas, US).

\section{Ethical Considerations}

The protocol was submitted and duly approved by the University of the Philippines Manila Research Ethics Board (UPMREB PED-2013-285-01) The primary investigators obtained consent from the mothers after a thorough explanation of the study. Participation was voluntary and withdrawal anytime during the study was respected. The possible risks of kangaroo mother care include apnea, hypothermia, and hyperthermia. Any adverse event in the participant automatically resulted in withdrawal from the study.

\section{RESULTS}

We screened 53 mother-baby dyads from March 3 to May 19, 2014. Two mother-baby dyads were ineligible for enrollment, as both mothers could not render KMC because of a maternal condition. An infant had deteriorating clinical status before day 3 of outcome assessment requiring transfer to critical care and removal from the analysis. The trial was stopped upon reaching the required number of infants. In total, we included 50 maternal-baby dyads for the analysis, equally divided into $\mathrm{KMC}$ and control groups.

Baseline characteristics of mothers included in the study are shown in Table 1 . Both groups were comparable in terms of maternal age, age of gestation, baby's sex and birthweight. There were more vaginal deliveries in KMC group, and more cesarean deliveries for the control group. There were no mothers with gestational diabetes randomly assigned to control group.

Mean serum prolactin levels on third day post-partum were 5,244.0 $( \pm 2,702.1) \mathrm{mL}$ and $4129.2( \pm 2485.3) \mathrm{mL}$ for the KMC and control group, respectively $(\mathrm{p}=0.250)$ (Table 2). Serum levels at seventh day post-partum were also higher for the $\mathrm{KMC}(4,968.8 \pm 2,425.8 \mathrm{mIU} / \mathrm{mL})$ compared to control group $(3,705.4 \pm 2,731.4 \mathrm{~mL})$, but this difference was not significant $(p=0.071)$. Volumes of expressed milk were significantly higher in the KMC group on the third day (29.6 $27.8 \mathrm{~mL} ; \mathrm{p}<0.001)$ and seventh day post-partum $(72.4 \pm$ $62.3 \mathrm{~mL} ; \mathrm{p}<0.001)$ compared to the control group. The rate of increase of breastmilk volume was also significantly greater in the $\mathrm{KMC}$ group $(\mathrm{p}=0.005)$

\section{DISCUSSION}

Initial milk volume is always a concern for mothers and is recognized as a reason for withholding exclusive breastfeeding. Literature has suggested that KMC promotes increased breast milk production crucial in the first week of life. Our study is the first proof-of-concept on the physiologic relationship between KMC and increased milk volume. We showed, as any proven galactagogue, that KMC can increase serum prolactin levels.

Table 1. Baseline characteristics

\begin{tabular}{|c|c|c|c|}
\hline Characteristics & $\mathrm{KMC}(\mathrm{n}=25)$ & Control $(n=25)$ & p value* \\
\hline Maternal Age, mean (SD), years & $27.6( \pm 7.8)$ & $28.2( \pm 6.6)$ & 0.378 \\
\hline Maturity aging, mean (SD), weeks & $34.4( \pm 1.8)$ & $34.1( \pm 2.2)$ & 0.265 \\
\hline $\begin{array}{l}\text { Mode of delivery (\%) } \\
\text { Vaginal delivery } \\
\text { Abdominal delivery }\end{array}$ & $\begin{array}{l}17(68) \\
8(32) \\
\end{array}$ & $\begin{array}{l}11(44) \\
14(56)\end{array}$ & 0.087 \\
\hline $\begin{array}{l}\text { Maternal Factors, frequency } \\
\text { Infection } \\
\text { Hypertension } \\
\text { Diabetes mellitus } \\
\text { Bronchial asthma } \\
\text { Systemic lupus erythematosus } \\
\text { Thyroid disease }\end{array}$ & $\begin{array}{c}11(44) \\
8(32) \\
4(16) \\
2(8) \\
- \\
1(4)\end{array}$ & $\begin{array}{c}11(44) \\
9(36) \\
- \\
2(8) \\
1(4) \\
-\end{array}$ & $<0.001$ \\
\hline $\begin{array}{l}\text { Neonatal Factors } \\
\text { Sex, } \mathrm{n}(\%), \text { male } \\
\text { Weight, mean (SD), grams }\end{array}$ & $\begin{array}{c}9(36) \\
1796( \pm 218)\end{array}$ & $\begin{array}{c}10(40) \\
1762( \pm 233)\end{array}$ & $\begin{array}{l}0.771 \\
0.594\end{array}$ \\
\hline
\end{tabular}


Table 2. Milk volume and prolactin levels of infants

\begin{tabular}{|c|c|c|c|}
\hline & $\mathrm{KMC}(\mathrm{n}=25)$ & Control $(n=25)$ & p-value ${ }^{1}$ \\
\hline \multicolumn{4}{|l|}{ Milk volume } \\
\hline Day 3 post-partum, mean (SD), mL & $29.6( \pm 27.8)$ & $16.3( \pm 26.1)$ & $<0.001$ \\
\hline Day 7 post-partum, mean (SD), $\mathrm{mL}$ & $72.4( \pm 62.3)$ & $47.3( \pm 43.8)$ & $<0.001$ \\
\hline$p$-value ${ }^{2}$ & 0.005 & 0.120 & \\
\hline \multicolumn{4}{|l|}{ Serum prolactin levels } \\
\hline Day 3 post-partum, mean (SD), mIU/L & $5244.0( \pm 2702.1)$ & $4129.2( \pm 2485.3)$ & 0.250 \\
\hline Day 7 post-partum, mean (SD), mIU/L & $4968.8( \pm 2425.8)$ & $3705.4( \pm 2731.4)$ & 0.071 \\
\hline$p$-value ${ }^{2}$ & 0.996 & 0.301 & \\
\hline Day of first successful latch, mean (SD), days ${ }^{3}$ & $3.7( \pm 2.2)$ & $4.1( \pm 1.5)$ & 0.248 \\
\hline
\end{tabular}

Literature proved various factors that affect prolactin secretion, including skin-to-skin contact, emotional state of the mother, and infant's presence. ${ }^{19,20} \mathrm{KMC}$ has major components that support these factors. And although it is already established that prolactin levels will physiologically decline postpartum, we observed a slower prolactin reduction for the experimental group compared to the control.

When expressed milk volumes were analyzed within groups, milk volume was seen to increase from third to seventh day post-partum, and a larger amount was observed for the experimental group across different observation periods. Initial volume of milk upon delivery is widely varied based on literature. ${ }^{21}$ Stabilization of milk supply occurs with the establishment of a regular pattern of feeding. ${ }^{21}$ In our study, preterm and low birthweight infants were enrolled, both of whom have irregular feeding pattern due to immature sucking reflex. We can then exclude the suckling stimulus for increase in milk volume and consider other factors, more specifically, hormonal control. In this study, we therefore hypothesize that the disparity in serum prolactin levels between the study groups explains the difference in milk volume. And though our study focuses on prolactin alone, we recognize that other hormones may also stimulate breast milk production including catecholamines, thyroid hormones and other sex steroids. ${ }^{15}$ This is another topic for future investigation.

There is large dispersion on data on milk volume. The methodology of milk collection has been based on several published studies. ${ }^{22,23}$ Several meta-analyses done on pharmacologic and herbal galactogogues observed large variation in milk volume and collection methods making it impossible to pool for an effect estimate..$^{15,20,24}$ Their group pointed out other parameters as surrogate outcomes that can be used to estimate breast milk volume. We recommend including infant's anthropometrics, urine output, diaper changes, and stool amount as surrogate outcomes for in vivo milk volume.
An inherent problem in any trial conducted with this intervention is blinding. ${ }^{19,25}$ Blinding ensures objectivity during outcome measurement. In this study, blinding for measurement of milk volume is almost impossible to achieve. The only outcome that can be concealed to the evaluator is serum prolactin level. We, therefore, conclude that among the outcomes measured in this study, serum prolactin levels are least affected by observer bias. Breast milk volume, on the other hand, is the most affected.

Our study contributes to the growing interest in the use of KMC to promote breastfeeding for mothers. Kangaroo mother care is a novel method that has been proven to have a positive impact in breastfeeding, but much of the studies have focused on success on exclusive breastfeeding, and less on the actual lactogenic effects of the intervention. ${ }^{26}$ Recognizing this need, Vaz did a study on 2012 on the effects of breast milk volume with $\mathrm{KMC}$ versus conventional care. ${ }^{27}$ They enrolled 30 mother-infant dyads equally divided between experimental and conventional intervention. It was a randomized, crossover trial involving low birth weight infants in NICU on expressed breast milk feeding. The experimental group had more milk volume compared with the conventional group $(28 \mathrm{~mL}$ vs $24.5 \mathrm{~mL}, \mathrm{p}<0.001)$. Another study was done by Pallas-Alonso, who also examined the effects of $\mathrm{KMC}$ on breast milk volume. ${ }^{26}$ They enrolled 36 mothers with low birth weight infants. There was no significant difference between the milk volume of $\mathrm{KMC}$ group $(104.3 \mathrm{~mL} \pm 55.1)$ and control group $(112.0 \mathrm{~mL} \pm 56.2)$.

\section{CONCLUSION AND RECOMMENDATION}

Kangaroo mother care may result in increased maternal serum prolactin levels that can result in increased breast milk production. This is crucial for initial and stabilization phases of milk letdown and milk production. We recommend further studies be done with larger sample sizes and to use surrogate clinical outcomes for indirect measurement of 
milk volume. Blinding of treatment groups may be difficult, but further enhancement of milk collection protocol can lead to more precise data. We also recommend doing other physiologic studies on KMC to demonstrate its beneficial effects not limited to perinatal care.

\section{Trial registry}

The study was prospectively registered in the AustraliaNew Zealand Clinical Trial Registry (https://www.anzctr. org.au/) Registration number ACTRN12614000218695 and under WHO Trial Registry U1111-1153-2711. Full trial protocol can be accessed at https://www.anzctr.org.au/Trial/ Registration/TrialReview.aspx?id=365839

\section{Ethical Registration}

The study was approved by the UP-Manila Research Ethics Board with Registration no. PED-2013-285-01 on January 20, 2014.

\section{Statement of Authorship}

All authors participated in the data collection and analysis and approved the final version submitted.

\section{Author Disclosure}

All authors declared no conflicts of interest.

\section{Funding Source}

The study was funded by Kangaroo Care Mother Foundation Philippines, Inc. The funding agency has no role on the study conceptualization, design, conduct, writing, and research dissemination.

\section{REFERENCES}

1. Acolet D, Sleath K, Whitelaw A. Oxygenation, heart rate and temperature in very low birthweight infants during skin-to-skin contact with their mothers. Acta Paediatr Scand. 1989; 78(2):189-93.

2. Charpak N, Ruiz-Pelaez JG, Figueroa de C Z, Charpak Y. Kangaroo mother versus traditional care for newborn infants $<=2000$ grams: a randomized, controlled trial. Pediatrics. 1997; 100(4):682-8.

3. Venancio SI, Almeida Hd. Kangaroo mother care: scientific evidences and impact on breastfeeding. Jornal de Pediatria. 2004; 80(5):s173-s180.

4. Ruiz-Pelaez JG. Kangaroo mother care, an example to follow from developing countries. BMJ 2004, 329(7475):1179-81.

5. Shrivastava SR, Shrivastava PS, Ramasamy J. Utility of kangaroo mother care in preterm and low birthweight infants. South African Family Practice. 2013; 55(4):340-4.

6. Warnock FF, Castral TC, Brant R, Sekilian M, Leite AM, de la Presa Owens S, et al. Brief report: Maternal kangaroo care for neonatal pain relief: a systematic narrative review. J Pediatr Psychol. 2010; 35(9): 975-84.

7. Mori R, Khanna R, Pledge D, Nakayama T. Meta-analysis of physiological effects of skin-to-skin contact for newborns and mothers. Pediatr Int. 2010; 52(2):161-70.
8. Föhe K, Kropf S, Avenarius S. Skin-to-skin contact improves gas exchange in premature infants. J Perinatol. 2000; 20(5):311-5.

9. Suman RPN, Udani R, Nanavati R. Kangaroo mother care for low birth weight infants: a randomized controlled trial. Indian Pediatr. 2008; 45(1):17-23.

10. Conde-Agudelo A, Diaz-Rossello JL. Kangaroo mother care to reduce morbidity and mortality in low birthweight infants. Cochrane Database Syst Rev 2003.

11. Hurst NM, Valentine CJ, Renfro L, Burns P, Ferlic L. Skin-to-skin holding in the neonatal intensive care unit influences maternal milk volume. J Perinatol. 1997; 17(3): 213-7.

12. Ruiz-Peláez JG, Charpak N, Cuervo LG. Kangaroo mother care, an example to follow from developing countries. BMJ. 2004; 329(7475):1179-81.

13. Tessier R, Cristo M, Velez S, Girón M, Sw, de Calume ZF, et al. Kangaroo mother care and the bonding hypothesis. Pediatrics. 1998 Aug; 102(2):e17. doi: 10.1542/peds.102.2.e17.

14. Bole-Feysot C, Goffin V, Edery M, Binart N, Kelly PA. Prolactin $(\mathrm{PRL})$ and its receptor: actions, signal transduction pathways and phenotypes observed in PRL receptor knockout mice. Endocr Rev. 1998; 19(3):225-68.

15. Anderson PO, Valdés V. A critical review of pharmaceutical galactagogues. Breastfeed Med. 2007; 2(4):229-42.

16. Ingram JC, Woolridge MW, Greenwood RJ, McGrath L. Maternal predictors of early breast milk output. Acta Pædiatrica. 1999; 88(5):493-9.

17. Powe CE, Puopolo KM, Newburg DS, Lönnerdal B, Chen C, Allen $\mathrm{M}$, et al. Effects of recombinant human prolactin on breast milk composition. Pediatrics. 2011 Feb; 127(2):e359-66.

18. Powe CE, Allen M, Puopolo KM, Merewood A, Worden S, Johnson LC, et al. Recombinant human prolactin for the treatment of lactation insufficiency. Clin Endocrinol. 2010; 73(5):645-53.

19. Moore ER, Anderson GC, Bergman N, Dowswell T. Early skinto-skin contact for mothers and their healthy newborn infants. Cochrane Database Syst Rev 2012(5): CD003519.

20. Forinash AB, Yancey AM, Barnes KN, Myles TD. The use of galactogogues in the breastfeeding mother. Ann Pharmacother. 2012; 46(10):1392-404.

21. Yamauchi Y, Yamanouchi I. breast-feeding frequency during the first 24 hours after birth in full-term neonates. Pediatrics. 1990; 86:171-5.

22. Estrella M, Mantaring J, David G, Taup M. A double-blind, randomized controlled trial on the use of malunggay (Moringa oleifera) for augmentation of the volume of breastmilk among non-nursing mothers of preterm infants. Phil J Ped. 2000; 49(1):3-6.

23. Yabes-Almirante C, Lim M. Enhancement of Breastfeeding among Hypertensive Mothers. In: Yabes-Almirante C, De Luna M (eds). Increasingly Safe and Successful Pregnancies. Elsevier Science. 1996, pp 279-86.

24. Gabay M. Galactogogues: medications that induce lactation. J Hum Lact. 2002; 18(3):274-9.

25. Conde-Agudelo A, Belizán JM. Kangaroo mother care to reduce morbidity and mortality in low birthweight infants. Cochrane Database Syst Rev 2011(3): CD002771.

26. Pallas-Alonso C, Sanchez-Martinez R, Miranda-Casabona E, Miguel-Trigoso A, Bailesteros-Lopez RM, Acuna-Muga J. Milk Extraction and Kangaroo Care. IX International Conference of on Kangaroo Mother Care. Ahmedabad, Gujarat, India; 2012.

27. Vaz MJ, Bhat SR, Chandrakala BS, Suman RPN. Impact of Kangaroo Mother Care on Lactation. IX International Conference of on Kangaroo Mother Care. Ahmedabad, Gujarat, India; 2012. 